\title{
EVALUATION OF THE SHIELDING PARAMETERS IMPLEMENTED IN THE PET-CT FACILITY AT THE NATIONAL INSTITUTE OF NUCLEAR MEDICINE \& ALLIED SCIENCES (NINMAS), DHAKA
}

\author{
M. N. Hossain ${ }^{1 *}$, M. S. Mia ${ }^{1}$, T. A. Biman ${ }^{2}$, H. Mehdi ${ }^{1}$, F. Begum ${ }^{1}$ \\ ${ }^{1}$ National Institute of Nuclear Medicine \& Allied Sciences, Dhaka-1000, Bangladesh \\ ${ }^{2}$ Physical Science Division, Bangladesh Atomic Energy Commission, Dhaka, Bangladesh \\ *Corresponding author e-mail: nahidhssn@yahoo.com
}

Received on 01.11.2019, Revised received on 25.11.2019, Accepted for publication on 30.11.2019

\begin{abstract}
Positron Emission Tomography (PET) combined with Computed Tomography (CT) is a very sensitive diagnostic imaging modality that consists of both functional and anatomical imaging into one combined scanning system. Because of the high energy of annihilation radiation $(511 \mathrm{keV})$ for PET tracers, shielding requirements are an important consideration in the design of a PET/CT facility. The shielding evaluation for adequate radiation protection of a PET/CT facility consists of the assessment of annual effective dose both to occupational workers and to members of the public's. The overall shielding assessment takes into account the radionuclides activity involved, the facility design, the scanning procedures, the expected number of patients per year and so on. The evaluation also depends upon the size of the PET/CT imaging room and patient's uptake rooms, the thickness and the physical materials of walls, floors and ceilings. In this work we verified the adequacy of shielding installed in the PET/CT facility at the National Institute of Nuclear Medicine \& Allied Sciences (NINMAS), Dhaka. The assessment results were compared to the provided shielding which was the design requirements.
\end{abstract}

Keywords: Positron Emission Tomography, Shielding parameters, Transmission factor, AAPM guide line for shielding calculation

\section{INTRODUCTION}

Positron Emission Tomography (PET)/Computed Tomography (CT) has become the best method in the diagnosis of tumor and cancer diseases. PET tomography uses the coincidence detection of the positron electron annihilation photons to acquire the projection data. This annihilation process usually results in the emission of two $511 \mathrm{keV}$ photons which travel in almost opposite directions (1). These $511 \mathrm{keV}$ annihilation photons are much higher energy than other diagnostic radiations. The most useful clinical PET radiopharmaceuticals is F-18 Fluoro-deoxy-glucose (F-18 FDG) which has been shown to have a beneficial impact on patient management and has become an established technique, particularly for the staging of some cancers (2). Due to the high energy of these annihilation radiations, shielding requirements for a PET/CT facility are significantly differ from most of the other diagnostic imaging facilities and this is very important consideration in the design of a PET/CT imaging facility (3-4). As a result, significant shielding is required in floors and ceilings as well as adjacent walls in a PET/CT facility. 
In this work we present the assessment of the shielding given in the PET/CT facility at NINMAS. Shielding calculations for adjacent walls, floors and ceilings were presented for both controlled and uncontrolled areas. The assessment results were also compared to the present shielding implemented in the facility. Formulas were used to calculate the shielding materials following the basic AAPM (American Association of Physicists in Medicine) guidelines (5).

\section{MATERIALS AND METHODS}

There are two PET/CT scanners installed in NINMAS. This one is very busy PET/CT facility and has 6 uptake rooms for administrated dose patients. After the uptake period, the patient has to void to clear the radioactivity that has accumulated in the bladder which is approximately $15-20 \%$ of the administered activity and these are excreted within the first two hours (6-7). For this reason a toilet should be reserved for PET/CT patients. In NINMAS there are two dedicated toilets engaged for PET/CT patients and these were placed close to the uptake rooms.

There are several factors involving the shielding calculations for PET/CT facility like number of patients imaged, amount of isotope administered per patient, length of time each patient remains in the department, location of the facility, general environs of the facility etc. The technologists who work directly with the PET/CT patients, receives the largest doses. The components of this dose include radiation from patient injections, patient positioning and the dose received at the imaging procedure (8-11).

The radiation dose rate from the patient is reduced by a significant factor due to the body absorbs some of the annihilation radiation. A number of papers have been published where direct measurements have been estimated at different directions from the patient (12-19). These published results were normalized for the amount of administered activity of radiotracer and distance from the patients, and were also corrected for radioactive decay back to the administration time. Based on these values, the AAPM task group recommends using a patient dose rate of 0.092 $\mu \mathrm{Sv} \mathrm{m}{ }^{2} / \mathrm{MBq} \mathrm{h}(3.4 \mu \mathrm{Sv} \mathrm{m} / \mathrm{h} / 37 \mathrm{MBq})$ immediately after administration.

Lead and concrete are the most likely shielding materials to be used in the PET/CT facility. Different types of attenuation coefficients have been used to estimate transmission requirements for PET/CT facilities. Several publications have been made for the narrow-beam, good geometry attenuation coefficients for lead and concrete. Under broad beam conditions the effective halfvalue layer of lead for shielding photons of $511 \mathrm{keV}$ has been reported in the range 4.1-5.5 mm (20-22). under narrow beam conditions the half value layer has been reported in the range 3.4-4.3 $\mathrm{cm}$ for the concrete at $511 \mathrm{keV}$ corresponding to the difference between normal density concrete $\left(2.35 \mathrm{~g} / \mathrm{cm}^{3}\right)$ and low density concrete $\left(1.84 \mathrm{~g} / \mathrm{cm}^{3}\right)$ which is commonly used in modern construction. Table-1 presents the Monte Carlo transmission factors for lead, concrete, and iron (5).

Due to the short half lives of PET tracers, the dose absorbed per hour is less than the product of the dose rate and the time. The total radiation dose received over a time period $t, D_{t}$, is less than the product of the dose rate $\left(D_{R}\right)$ and time $(t)$ by a factor of

$$
\mathrm{R}_{\mathrm{T}}=\mathrm{D}_{\mathrm{t}} /\left(\mathrm{D}_{\mathrm{R}} \times \mathrm{t}\right)=1.443 \times\left(\mathrm{T}_{1 / 2} / \mathrm{t}\right) \times\left(1-\exp \left(-0.693 \mathrm{t} / \mathrm{T}_{1 / 2}\right)\right) \ldots \ldots \text { (1) }
$$

$\mathrm{T}_{1 / 2}$ is the half life of F-18 and the value is 110 minutes. This corresponds dose reduction factors $\mathrm{R}_{\mathrm{T}}$ are $0.91,0.83$, and 0.76 for $t=30,60$, and $90 \mathrm{~min}$, respectively for F-18. 
Table1: Broad beam Transmission Factors at $511 \mathrm{keV}$ in lead, concrete, iron.

\begin{tabular}{llll}
\hline & \multicolumn{1}{c}{ Transmission Factors $^{\mathbf{c}}$} \\
\hline Thickness $^{\mathbf{a}, \mathbf{b}}$ & Lead & Concrete $^{\mathbf{c}}$ & Iron \\
\hline 0 & 1.0000 & 1.0000 & 1.0000 \\
1 & 0.8912 & 0.9583 & 0.7484 \\
3 & 0.7873 & 0.9088 & 0.5325 \\
4 & 0.6905 & 0.8519 & 0.3614 \\
5 & 0.6021 & 0.7889 & 0.2353 \\
6 & 0.5227 & 0.7218 & 0.1479 \\
7 & 0.4522 & 0.6528 & 0.0905 \\
8 & 0.3903 & 0.5842 & 0.0542 \\
9 & 0.3362 & 0.5180 & 0.0319 \\
10 & 0.2892 & 0.4558 & 0.0186 \\
12 & 0.2485 & 0.3987 & 0.0107 \\
14 & 0.1831 & 0.3008 & 0.0035 \\
16 & 0.1347 & 0.2243 & 0.0011 \\
18 & 0.0990 & 0.1662 & 0.0004 \\
20 & 0.0728 & 0.1227 & 0.0001 \\
25 & 0.0535 & 0.0904 & \\
30 & 0.0247 & 0.0419 & \\
40 & 0.0114 & 0.0194 & \\
50 & 0.0024 & 0.0042 & \\
\hline
\end{tabular}

${ }^{\text {a}}$ Thickness in $\mathrm{mm}$ for lead.

${ }^{\mathrm{b}}$ Thickness in $\mathrm{cm}$ for concrete and iron.

${ }^{\mathrm{c}}$ Concrete density $=2.35 \mathrm{~g} / \mathrm{cm}^{3}$.

\section{Assessment of the Uptake (Patient Waiting Area) Room Shielding}

Six uptake rooms are provided in the facility due to the significant number of patients. All uptake (post dose admin waiting) room's, PET/CT room's and other associate room's dimension were shown in Table 2.

The shielding calculations use a target level of $5 \mathrm{mSv} /$ year in controlled areas to be consistent with ALARA recommendations. Transmission factor $\mathrm{X}$ for the shielding of the uptake rooms for the patients undergoing PET/CT scans considering ALARA level, were calculated by using the following formula from AAPM method.

$\mathrm{X}=10.9 \times \mathrm{S} \times \mathrm{d}(\mathrm{m})^{2} /\left(\mathrm{T} \times \mathrm{B}_{\mathrm{W}} \times \mathrm{A}_{0}(\mathrm{MBq}) \times \mathrm{T}_{\mathrm{U}}(\mathrm{h}) \times \mathrm{R}_{\mathrm{TU}}\right)$

$\mathrm{X}=1090 \times \mathrm{d}(\mathrm{m})^{2} /\left(\mathrm{T} \times \mathrm{B}_{\mathrm{W}} \times \mathrm{A}_{0}(\mathrm{MBq}) \times \mathrm{T}_{\mathrm{U}}(\mathrm{h}) \times \mathrm{R}_{\mathrm{TU}}\right)$

The detail parameters values have been shown in Table 3.

After calculating the transmission factor, the shielding requirement is calculated using the Table 1. 
Table2: Dimension of associated PET /CT room.

\begin{tabular}{lll}
\hline Sl. No. & Room name & Dimension in meter \\
\hline 1 & PET/CT scanning room 1 (Philips) & $6.88 \times 6.70$ \\
2 & PET/CT Console room & $5.64 \times 5.90$ \\
3 & PET/CT scanning room 1 (GE) & $5.51 \times 7.01$ \\
4 & Post Dose Admin Waiting 1 & $3.48 \times 1.85$ \\
5 & Post Dose Admin Waiting 2 & $3.48 \times 1.77$ \\
6 & Post Dose Admin Waiting 3 & $3.48 \times 1.85$ \\
7 & Post Dose Admin Waiting 4 & $3.60 \times 1.77$ \\
8 & Post Dose Admin Waiting 5 & $3.60 \times 1.80$ \\
9 & Post Dose Admin Waiting 6 & $1.70 \times 3.88$ \\
10 & Hot Lab & $2.71 \times 1.77$ \\
11 & Isotope dispensing room & $1.74 \times 1.77$ \\
\hline
\end{tabular}

Assessment of the Imaging room Shielding

The delay required by the uptake phase between the administration of the radiopharmaceutical and the actual imaging, the activity in the patient is decreased by

$\mathrm{Q}_{\mathrm{U}}=\exp \left[-0.693 \times \mathrm{T}_{\mathrm{U}}(\mathrm{min}) / 110\right] \ldots \ldots$ (3)

Where $\mathrm{T}_{\mathrm{U}}$ is the uptake time. The decay factor for $\mathrm{F}-18$ at $1 \mathrm{~h} \mathrm{Q}_{\mathrm{U}}$ is equal to $\exp (-0.693 \mathrm{x}$ $60 / 110)=0.68$.

Transmission factor for the two imaging room is calculated by using the following formula $\mathrm{X}=1280 \times \mathrm{d}\left(\mathrm{m}^{2}\right) /\left(\mathrm{T} \times \mathrm{B}_{\mathrm{W}} \times \mathrm{A}_{\mathrm{o}}(\mathrm{MBq}) \times \mathrm{Q}_{\mathrm{U}} \times \mathrm{t}_{\mathrm{I}}(\mathrm{h}) \times \mathrm{R}_{\mathrm{tI}}\right) \ldots \ldots$ (4)

Decreasing dose rate 0.85 as generally the patient will void prior to imaging, removing approximately $15 \%$ of the administered activity.

The detail parameters values have been shown in Table 3 .

After calculate the transmission factor, shielding requirement is been calculated by using the Table 1.

Table 3: Different parameters used in formulae.

\begin{tabular}{cll}
\hline SI No. & Details of parameters & Value \\
\hline 1 & Administered activity per patient $\mathrm{A}_{\mathrm{o}}$ & $280 \mathrm{MBq}$ \\
2 & Occupancy factor, $\mathrm{T}$ & 1 \\
3 & Distance from source (patient) to barrier d & $\mathrm{d} \mathrm{in} \mathrm{m}$ \\
4 & Weekly dose limit for ALARA levels in controlled areas $\mathrm{S}$ & $100 \mu \mathrm{Sv}$ \\
5 & Total patients in a week & 100 \\
6 & Patients per waiting room in a week $\mathrm{B}_{\mathrm{W}}$ & 17 \\
7 & Dose reduction factor $\mathrm{R}_{\mathrm{T}}$ for uptake time $60 \mathrm{~min}$ & 0.91 \\
8 & Decay factor for uptake time 60 min, $\mathrm{Q}_{\mathrm{U}}$ & 0.68 \\
9 & Imaging time t & $30 \mathrm{~min}$ \\
10 & Dose reduction factor during imaging time $\mathrm{R}_{\mathrm{tI}}$ & 0.95 \\
\hline
\end{tabular}




\section{Assessment of shielding for rooms above and below the PET/CT unit}

The $511 \mathrm{keV}$ annihilation photons of F-18 are so penetrating. So, it is necessary to consider uncontrolled areas above and below the PET/CT facility as well as those adjacent on the same level. Figure 1 shows the source and target distances that apply in these cases. Typically, one assumes that the patient (source of the activity) is $1 \mathrm{~m}$ above the floor. The dose rate is calculated at $0.5 \mathrm{~m}$ above the floor for rooms above the source, and at $1.7 \mathrm{~m}$ above the floor for rooms below the source.

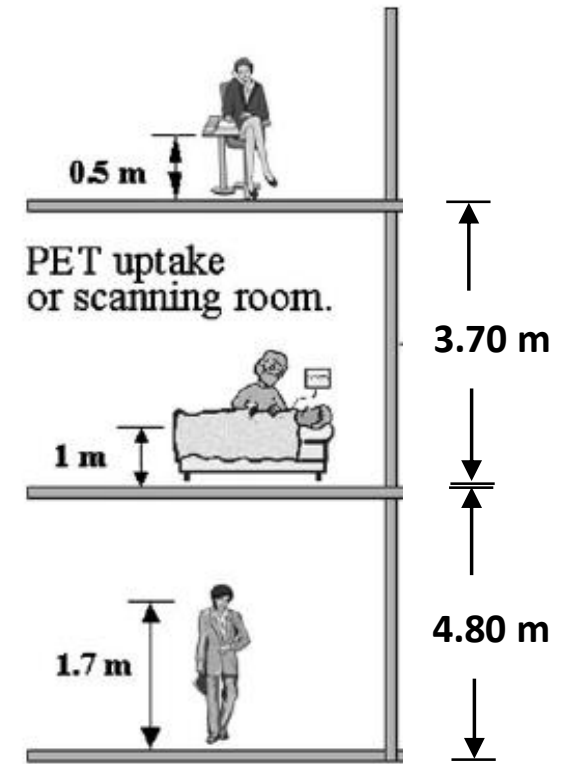

Fig. 1: Distance estimation above and below the PET/CT unit

\begin{tabular}{c|l}
\hline $\begin{array}{c}\text { Above the } \\
\text { PET/CT Unit }\end{array}$ & $\begin{array}{l}\text { Room height }=3.70 \mathrm{~m} \text {, bed height from floor= } 1 \mathrm{~m} \\
\text { Roof height from the source }=3.70-1=2.70 \mathrm{~m} \\
\text { Distance from source to target }=2.70+0.5=3.20 \mathrm{~m}\end{array}$ \\
\hline Below the & $\begin{array}{l}\text { Room height }=4.80 \mathrm{~m}, \text { bed height from floor }=1 \mathrm{~m} \\
\text { Parget height }=1.70 \mathrm{~m}, \text { target to roof height }=4.80-1.70=3.10 \mathrm{~m} \\
\text { Distance from source to target }=3.10+1.0=4.10 \mathrm{~m}\end{array}$ \\
\hline
\end{tabular}

The weekly dose of post dose patients waiting room at a distance $d$ from the source is calculated as $0.092 \mu \mathrm{Sv} \mathrm{m}{ }^{2} / \mathrm{MBq} \mathrm{h} \times \mathrm{B}_{\mathrm{W}} \times \mathrm{A}_{0}(\mathrm{MBq}) \times \mathrm{t}_{\mathrm{U}}(\mathrm{h}) \times \mathrm{R}_{\mathrm{TU}} / \mathrm{d}(\mathrm{m})^{2}$

The weekly dose of PET/CT imaging room at a distance $d$ from the source is calculated as $0.092 \mu \mathrm{Sv} \mathrm{m}{ }^{2} / \mathrm{MBq} \mathrm{h} \times \mathrm{B}_{\mathrm{W}} \times \mathrm{A}_{0}(\mathrm{MBq}) \times 0.85 \times \mathrm{Q}_{\mathrm{U}} \times \mathrm{t}_{\mathrm{l}}(\mathrm{h}) \times \mathrm{R}_{\mathrm{tI}} / \mathrm{d}(\mathrm{m})^{2}$

After calculation of the transmission factor; use the Table1 to find the shielding requirement. 


\section{RESULTS}

The required shielding has been calculated for PET/CT imaging rooms and the most important post dose administrated patient's waiting rooms. The transmission factors have been calculated and the required shielding has been assessed from the table (Table 1) of broad beam transmission factors at $511 \mathrm{keV}$ in lead and concrete. The broad beam transmission factors table was mentioned in AAPM guideline. From the calculation, the shielding requirements for the walls of PET/CT scanner rooms have been assessed almost from 6 to $9 \mathrm{~cm}$ concrete (equivalent $\sim 3-6 \mathrm{~mm}$ lead). For the patient waiting rooms, the shielding requirements have been assessed 4 to $23 \mathrm{~cm}$ concrete (equivalent $\sim 1.5-20 \mathrm{~mm}$ lead). The shielding for rooms above and below the PET/CT unit have been calculated 1 to $7.5 \mathrm{~cm}$ concrete. The details of the required shielding and given shielding have been showed at the Table 4, 5 and 6 . It was observed that the shielding requirement was found higher in the post dose administrated patient waiting rooms than PET/CT imaging room due to the room size and the more time of patients stay after administration dose in patient's waiting rooms.

Exposure rate coming from the patient kept in the patient waiting room were measured at each outer wall of all uptake rooms and PET/CT rooms by using survey meter. Measured data were found to be at almost background level for most of the walls. Shielding thickness given is pretty more than the calculated value according to the AAPM. It was seen form the graph (Fig. 2) that the given thickness is 30 to $38 \mathrm{~cm}$ concrete for the uptake room-1 where the calculated thickness is 4 to $23 \mathrm{~cm}$. So the given thickness provides more safety.

Table 4: Evaluation of the shielding implemented for Post dose admin waiting rooms

\begin{tabular}{|c|c|c|c|c|c|c|c|}
\hline Area & & $\begin{array}{c}\text { Distanc } \\
\text { e in m }\end{array}$ & $\begin{array}{c}\text { Rt Dose } \\
\text { reduction } \\
\text { factor }\end{array}$ & $\begin{array}{c}\text { Result } \\
\text { Transmission } \\
\text { factor }\end{array}$ & $\begin{array}{c}\text { Calculate } \\
\text { d } \\
\text { Concrete } \\
\text { in cm } \\
\end{array}$ & $\begin{array}{c}\text { Calculate } \\
\text { d Pb in } \\
\text { mm }\end{array}$ & $\begin{array}{c}\text { Given } \\
\text { concrete } \\
(\mathrm{cm})\end{array}$ \\
\hline Post dose & $\mathrm{E}$ & 1.4 & 0.83 & 0.5408 & 8 & 5 & 38 \\
\hline Admin waiting - & W & 0.45 & 0.83 & 0.0559 & 23 & 20 & 30 \\
\hline \multirow[t]{2}{*}{1} & $\mathrm{~N}$ & 1.74 & 0.83 & 0.8353 & 4 & 1.5 & 30 \\
\hline & $\mathrm{S}$ & 1.74 & 0.83 & 0.8353 & 4 & 1.5 & 30 \\
\hline Post dose & $E$ & 1.32 & 0.83 & 0.4807 & 8 & 5 & 30 \\
\hline Admin waiting - & W & 0.45 & 0.83 & 0.0559 & 23 & 20 & 30 \\
\hline \multirow[t]{2}{*}{2} & $\mathrm{~N}$ & 1.74 & 0.83 & 0.8353 & 4 & 1.5 & 30 \\
\hline & $\mathrm{S}$ & 1.74 & 0.83 & 0.8353 & 4 & 1.5 & 30 \\
\hline Post dose & $\mathrm{E}$ & 1.4 & 0.83 & 0.5408 & 8 & 5 & 30 \\
\hline Admin waiting - & W & 0.45 & 0.83 & 0.0559 & 23 & 20 & 30 \\
\hline \multirow[t]{2}{*}{3} & $\mathrm{~N}$ & 1.74 & 0.83 & 0.8353 & 4 & 1.5 & 30 \\
\hline & $\mathrm{S}$ & 1.74 & 0.83 & 0.8353 & 4 & 1.5 & 30 \\
\hline Post dose & $\mathrm{E}$ & 1.00 & 0.83 & 0.4807 & 13 & 8 & 30 \\
\hline Admin waiting - & W & 0.77 & 0.83 & 0.0559 & 16 & 13 & 18 \\
\hline \multirow[t]{2}{*}{4} & $\mathrm{~N}$ & 1.8 & 0.83 & 0.8939 & 4 & 1.5 & 30 \\
\hline & $\mathrm{S}$ & 1.8 & 0.83 & 0.8939 & 4 & 1.5 & 18 \\
\hline Post dose & $\mathrm{E}$ & 1.35 & 0.83 & 0.5029 & 8 & 5 & 18 \\
\hline Admin waiting - & W & 0.45 & 0.83 & 0.0559 & 23 & 20 & 30 \\
\hline \multirow[t]{2}{*}{5} & $\mathrm{~N}$ & 1.8 & 0.83 & 0.8939 & 4 & 1.5 & 30 \\
\hline & $\mathrm{S}$ & 1.8 & 0.83 & 0.8939 & 4 & 1.5 & 18 \\
\hline Post dose & $\mathrm{N}$ & 1.25 & 0.83 & 0.4311 & 9 & 6 & 18 \\
\hline Admin waiting - & $\mathrm{S}$ & 0.45 & 0.83 & 0.0559 & 23 & 20 & 30 \\
\hline \multirow[t]{2}{*}{6} & $\mathrm{E}$ & 1.94 & 0.83 & 1.0384 & 0 & 0 & 30 \\
\hline & W & 1.94 & 0.83 & 1.0384 & 0 & 0 & 30 \\
\hline
\end{tabular}


Table 5: Evaluation of the Shielding implemented for PET-CT Imaging room

\begin{tabular}{|c|c|c|c|c|c|c|c|c|}
\hline & & $\begin{array}{l}\text { Distance } \\
\text { in } \mathbf{m}\end{array}$ & $\begin{array}{c}\text { Dose } \\
\text { reduction } \\
\text { factor } \\
\end{array}$ & $\begin{array}{c}\text { Total } \\
\text { weekly } \\
\text { dose } \\
\end{array}$ & $\begin{array}{c}\text { Transmission } \\
\text { factor }\end{array}$ & $\begin{array}{c}\text { Calculated } \\
\text { Concrete } \\
(\mathrm{cm})\end{array}$ & $\begin{array}{c}\text { Calculated } \\
\text { Pb (mm) }\end{array}$ & $\begin{array}{c}\text { Given } \\
\text { concrete } \\
(\mathrm{cm}) \\
\end{array}$ \\
\hline PET/CT & $E$ & 3.44 & 0.91 & 28.6245 & 0.6987 & 6 & 3 & 38 \\
\hline (Philips) & $\mathrm{W}$ & 3.44 & 0.91 & 28.6245 & 0.6987 & 6 & 3 & 38 \\
\hline \multirow[t]{2}{*}{ Scanner Room } & $\mathrm{N}$ & 3.35 & 0.91 & 30.1832 & 0.6626 & 6 & 3 & 38 \\
\hline & $\mathrm{S}$ & 3.35 & 0.91 & 30.1832 & 0.6626 & 6 & 3 & 38 \\
\hline PET/CT (GE) & $\mathrm{E}$ & 2.82 & 0.91 & 42.5948 & 0.46954 & 9 & 6 & 38 \\
\hline Scanner & $\mathrm{W}$ & 2.82 & 0.91 & 42.5948 & 0.46954 & 9 & 6 & 38 \\
\hline \multirow[t]{2}{*}{ Room } & $\mathrm{N}$ & 2.95 & 0.91 & 38.9234 & 0.51383 & 8 & 5 & 38 \\
\hline & $\mathrm{S}$ & 2.95 & 0.91 & 38.9234 & 0.51383 & 8 & 5 & 38 \\
\hline
\end{tabular}

Table 6: Evaluation of the Shielding implemented for above and below the facility

\begin{tabular}{|c|c|c|c|c|c|c|}
\hline \multicolumn{2}{|c|}{ Area } & $\begin{array}{l}\text { Distance } \\
\text { in } \mathbf{m}\end{array}$ & $\begin{array}{c}\text { Total weekly } \\
\text { dose }\end{array}$ & $\begin{array}{c}\text { Transmission } \\
\text { factor }\end{array}$ & $\begin{array}{c}\text { Calculated } \\
\text { concrete }(\mathrm{cm})\end{array}$ & $\begin{array}{c}\text { Given } \\
\text { concrete } \\
(\mathrm{cm})\end{array}$ \\
\hline \multirow[t]{2}{*}{$\begin{array}{l}\text { Above } \\
\text { the roof }\end{array}$} & $\begin{array}{l}\text { post dose } \\
\text { admin }\end{array}$ & 3.2 & 35.4955 & 0.5635 & 7.5 & 25 \\
\hline & $\begin{array}{l}\mathrm{PET} / \mathrm{CT} \\
\text { Imaging } \\
\text { room }\end{array}$ & 3.2 & 33.0792 & 0.6046 & 7 & 25 \\
\hline $\begin{array}{l}\text { Below } \\
\text { the }\end{array}$ & $\begin{array}{l}\text { post dose } \\
\text { admin }\end{array}$ & 4.1 & 21.6224 & 0.9249 & 2 & 25 \\
\hline Floor & $\begin{array}{l}\mathrm{PET} / \mathrm{CT} \\
\text { Imaging } \\
\text { room }\end{array}$ & 4.1 & 20.1505 & 0.9925 & 1 & 25 \\
\hline
\end{tabular}

The PET/CT unit is placed in the $1^{\text {st }}$ floor of the hospital.

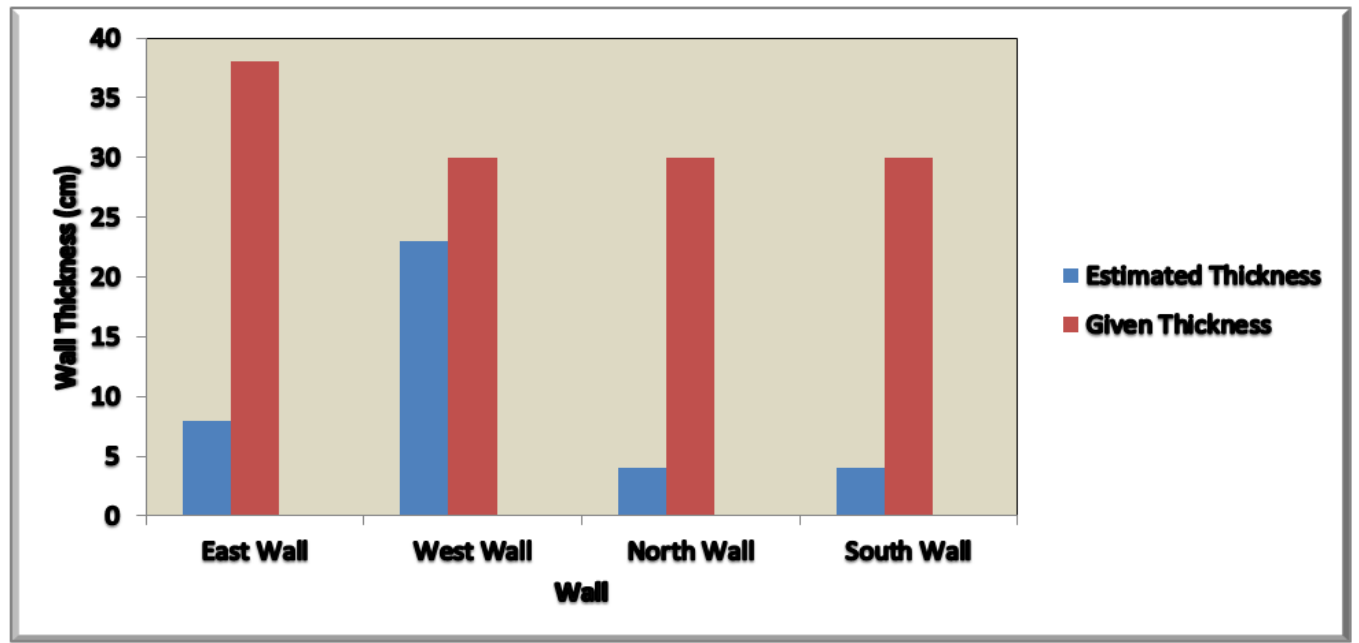

Fig. 2: Comparison of the estimated thickness with the given thickness of post dose admin waiting-1 room's walls 


\section{DISCUSSIONS}

It is suggested that, when PET/CT scanning is introduced, some additional shielding is likely to be required within the facility so that staff and members of the public are protected. The dose rates and transmission factors of PET radionuclides are significantly higher than the other nuclear medicine radionuclides like ${ }^{99 \mathrm{~m}} \mathrm{Tc}$. The shielding requirements in the walls for the CT system will have only a modest shielding effect for the $511 \mathrm{keV}$ annihilation radiation. Because the HVL of the CT x-rays is so much smaller than that for $511 \mathrm{keV}$ annihilation radiation; a room that is shielded to meet the general public levels for PET ( $1 \mathrm{mSv} /$ year) is no need additional shielding for the CT component. The calculated shielding requirements for the PET/CT unit were found $<25 \mathrm{~cm}$ concrete in the all walls. At present the given concrete thickness was provided more than the estimated thickness in the whole PET/CT facility at NINMAS which are safer for the patients, radiation workers, patient's attendants and member of the public. The PET/CT unit was established with fulfillment of these shielding requirements. The radiation doses to the staff and public were kept to acceptable limits.

\section{CONCLUSION}

PET/CT facilities require somewhat different design than conventional nuclear medicine departments and are more likely to involve additional radiation shielding. By use of appropriate design, by providing appropriate shielding and by maintaining good operating practices, radiation doses to staff and the public can be kept to acceptable limits. The mathematical analysis of the shielding estimation is most important task for a PET/CT facility. The shielding calculation is a regulatory requirement to establish a PET/CT facility in Bangladesh. Proper safe planning with supplier, facility engineer and a qualified medical physicist are essential to make a cost effective and safe design maintaining radiation safety standards.

\section{REFERENCES}

1. M. D. Harpen, Positronium: Review of symmetry, conserved quantities and decay for the radiological physicist, Med. Phys. 31, 57-61 (2004).

2. Ell PJ, The contribution of PET/CT to patient management. Br. J. Radiol ;79,32-6 (2006).

3. B. M. Methe, "Shielding design for a PET imaging suite: a case study, Health Phys. 84, S83-88, (2003).

4. J. C. Courtney et al., Photon shielding for a positron emission tomography suite, Health Phys. 81, S24$28,(2001)$.

5. Mark T. Madsen et al., “AAPM Task Group 108: PET and PET/CT Shielding Requirements, Med. Phys. 33(1), (2006).

6. D. Swanson et al., Pharmaceuticals in Medical Imaging, Macmillan Publishing Company, New York, (1990).

7. S. C. Jones et al., The radiation dosimetry of 2 [F-18]fluoro-2-deoxy-Dglucose in man, J. Nucl. Med. 23, 613-617(1982).

8. V. A. McCormick and J. A. Miklos, Radiation dose to positron emission tomography technologists during quantitative versus qualitative studies, J. Nucl. Med. 34, 769-772 (1993).

9. M. Griff, T. Berthold, and A. Buck, Radiation exposure to sonographers from fluorine-18-FDG PET patients, J. Nucl. Med. Technol. 28, 186- 187 (2000). 
10. C. D. Greaves and W. B. Tindale, Dose rate measurements from radiopharmaceuticals: Implications for nuclear medicine staff and for children with radioactive parents, Nucl. Med. Commun. 20, 179-187 (1999).

11. N. L. McElroy, Worker dose analysis based on real time dosimetry, Health Phys. 74, 608-609 (1998).

12. C. Chiesaet et al., Radiation dose to technicians per nuclear medicine procedure: comparison between technetium-99m, gallium-67, and iodine- 131 radiotracers and fluorine-18 fluorodeoxyglucose, Eur. J. Nucl. Med. 24, 1380-1389 (1997).

13. A. Bixler et al., Practical aspects of radiation safety for using fluorine-18, J. Nucl. Med. Technol. 27, 14-16 (1999).

14. T. M. Lundberg et al., Measuring and minimizing the radiation dose to nuclear medicine technologists, J. Nucl. Med. Technol. 30, 25-30 (2002).

15. T. F. Brown and N. J. Yasillo, Radiation safety considerations for PET centers, J. Nucl. Med. Technol. 25, 98-102 (1997);

16. B. Cronin et al., Are restrictions to behaviour of patients required following fluorine-18 fluorodeoxyglucose positron emission tomographic studies?, Eur. J. Nucl. Med. 26, 121-128 (1999).

17. B. W. Zeff and M. V. Yester, Patient self-attenuation and technologist dose in positron emission tomography, Med. Phys. 32, 861-865 (2005).

18. S. White et al., Occupational exposure in nuclear medicine and PET, Clin Positron Imaging 3, 127-129 (2000).

19. N. A. Benatar et al., Radiation dose rates from patients undergoing PET: Implications for technologists and waiting areas, Eur. J. Nucl. Med. 27, 583-589 (2000).

20. National Council on Radiation Protection and Measurements, Sources and Magnitude of Occupational and Public Exposures from Nuclear Medicine Procedures, NCRP Report No. 124 (National Council on Radiation Protection and Measurements, Bethesda, 1996), Chap. 4.

21. L. M. Unger and D. K. Trubey, Specific Gamma-Ray Dose Constants for Nuclides Important to Dosimetry and Radiological Assessment, ORNL/RSIC-45, as abstracted in Handbook of Health Physics and Radiological Health, 3rd ed., edited by B. Shleien, L. A. Slaback, Jr., and B. K. Birky (Williams and Wilkins, Baltimore, 1998), pp 6.7-6.14.

22. J.C. Courtney et al., Photon shielding for a positron emission tomography suite, Health Phys. 81, S24S28 (2001) 
